\title{
Perfil de auto-anticorpos em índios das tribos Kaingang e Guarani do Sul do Brasil
}

\author{
Shirley Ramos da Rosa Utiyama, ${ }^{1}$ Joel Guardiano, ${ }^{1}$ Maria Luiza \\ Petzl-Erler, ${ }^{2}$ Valmir Mocelim ${ }^{1}$ e lara José T. de Messias-Reason ${ }^{1}$
}

RESUMO O presente estudo teve por objetivo investigar o perfil de auto-anticorpos em 241 amostras de sangue de 176 indios Kaingang e 65 indios Guarani de três populações das reservas indígenas do Rio das Cobras e Ivaí, no Estado do Paraná, região Sul do Brasil. Foram investigados os anticorpos antimúsculo liso, antimitocôndrias, antinucleares, anticélulas gástricas parietais e antimicrossomas de fígado e rim, por método de imunofluorescência indireta. Os resultados foram comparados com os de um grupo de 100 indivíduos sadios, pertencentes à população geral. $\mathrm{Ob}$ teve-se uma positividade total de $9 \%$ para a população indígena investigada e $4 \%$ para os controles, com resultado significativo para prevalência dos anticorpos antimúsculo liso nas populações Kaingang e Guarani do Rio das Cobras $(\mathrm{P}=0,03)$. É provável que as práticas culturais envolvendo escarificações, tatuagens e processamento oral de alimentos, aliadas ao processo de aculturação e maior convívio com populações não indígenas, exponham os índios a doenças infecciosas anteriormente inexistentes entre os mesmos. Possíveis mecanismos de mimetismo molecular a antígenos virais ou bacterianos poderiam explicar a presença desses auto-anticorpos nessas populações indígenas.

Estudos recentes evidenciam o interesse de pesquisadores e órgãos de saúde pública nas mais diversas populações indígenas $(1,2)$. Investigações sobre aspectos demográficos, epidemiológicos, genéticos e culturais de diferentes tribos têm sido realizadas ao longo dos anos (3-5). Tais estudos têm mostrado que os altos índices de doenças infecciosas (6-8) e de problemas nutricionais $(9,10)$, assim como o consumo excessivo de substâncias de abuso, estão diretamente ligados aos

\footnotetext{
Universidade Federal do Paraná, Departamento de Patologia Médica, Laboratório de Imunopatologia, Curitiba, PR, Brasil. Correspondência e pedidos de separatas devem ser enviados a Iara José T. de Messias-Reason no seguinte endereço: Laboratório de Imunopatologia, Departamento de Patologia Médica, Universidade Federal do Paraná, Rua Padre Camargo 280, CEP 80060-900, Curitiba, PR, Brasil. Fax: +55-41-264-4191; e-mail: imunopat@hc. ufpr.br

2 Universidade Federal do Paraná, Departamento de Genética, Laboratório de Imunogenética.
}

níveis de mortalidade e morbidade nessas populações.

No Canadá, investigações revelaram um risco elevado de mortalidade causada por alcoolismo, suicídio e pneumonia entre grupos nativos quando comparados à população geral. Alguns subgrupos apresentam maior predisposição a doenças infecciosas e respiratórias, além de problemas nutricionais, inclusive obesidade. A ocorrência de diabetes melito tem sido relatada em até $6 \%$ da população adulta nessas tribos do Canadá (1). Além disso, outras doenças como câncer, cirrose, doenças cardíacas e hipertensão têm sido descritas em índios americanos e do Alasca (9).

Os Kaingang e Guarani constituem as duas maiores tribos de ameríndios que ainda vivem no Sul do Brasil, podendo também ser encontrados no Paraguai e no Norte da Argentina. Estes dois gru- pos indígenas são culturalmente distintos entre si. Os Guarani pertencem ao grupo lingüístico Tupi, e os Kaingang, ao grupo lingüístico Gê. Os Guarani são nômades e costumam viver perto de grandes rios, organizando-se em vários subgrupos. Os Kaingang, por sua vez, são seminômades e vivem nos planaltos. A atividade básica das duas tribos se restringe à agricultura, caça e pesca. Atualmente, apesar da redução populacional que sofreram com a colonização, as tribos indígenas sul-brasileiras estão distribuídas em várias reservas administradas pelo governo federal, sendo que muitas delas são compartilhadas pelos Guarani e Kaingang, que habitam em diferentes vilas. Embora tenham passado por um intenso processo de aculturação, estes indígenas ainda têm costumes bastante distintos do restante da população brasileira, inclusive a endogamia. 
Nos últimos anos, estudos pioneiros relativos ao polimorfismo de marcadores genéticos foram realizados em aproximadamente 340 indivíduos destas tribos, incluindo a tipagem dos antígenos HLA (11) e dos componentes C3 e Bf do sistema do complemento $(12,13)$.

Embora existam alguns relatos de doenças auto-imunes e pesquisa de auto-anticorpos em populações indígenas em geral $(2,4,14)$, tais estudos são escassos nos índios do Brasil (15). Dessa forma, o presente trabalho teve por objetivo investigar o perfil de auto-anticorpos em índios das tribos Kaingang e Guarani e comparar os resultados com um grupo controle da população geral.

\section{MATERIAIS E MÉTODOS}

\section{População estudada}

Foram estudados 241 voluntários adultos, sadios, de três tribos das reservas indígenas do Rio das Cobras e
Ivaí, no Estado do Paraná, Sul do Brasil (figura 1). Estas tribos compreendiam 103 índios Kaingang do Rio das Cobras (KRC); 73 índios Kaingang do Rio Ivaí (KIV); e 65 índios Guarani do Rio das Cobras (GRC).

A coleta de sangue foi realizada nos indivíduos que se apresentaram espontaneamente no posto de coleta, após autorização da Fundação Nacional do Índio (FUNAI) e dos líderes das diferentes tribos para a realização de um amplo estudo, inclusive com coleta das amostras. Todos os indivíduos foram submetidos a uma avaliação médica convencional, compreendendo exame físico completo e história clínica (peso, temperatura corporal, pressão arterial, doenças de pele, doenças respiratórias, diarréia, desnutrição, alcoolismo e doenças na família). As amostras de sangue foram submetidas a exame sorológico para sífilis, doença de Chagas, hepatites e AIDS. No ano em que foram coletadas as amostras (1990), a população de cada tribo era a seguinte: em Rio das Cobras, 1800 índios Kaingang e 400 Guarani; e em Ivaí, 700 Kaingang. Os dados levantados demonstraram que, apesar do avançado estágio de aculturação, o grau de miscigenação com outros grupos étnicos ainda era baixo.

As amostras de sangue foram coletadas nas regiões do Rio das Cobras e Ivaí e transportadas, em gelo, ao laboratório de imunogenética da Universidade Federal do Paraná (UFPR), onde foram centrifugadas. Os soros foram aliquotados e conservados a $-70^{\circ} \mathrm{C}$ até o momento de uso.

\section{Controles}

Para fins de controle, foram analisadas amostras de sangue coletadas aleatoriamente de 100 voluntários caucasóides, sadios (36 do sexo feminino e 64 do sexo masculino), com idade entre 18 e 60 anos (média $=33,4$ ), pertencentes à população geral do Estado

FIGURA 1. Localização das reservas indígenas do Rio das Cobras (Kaingang e Guarani) e Ivaí (Kaingang), Estado do Paraná, Brasil

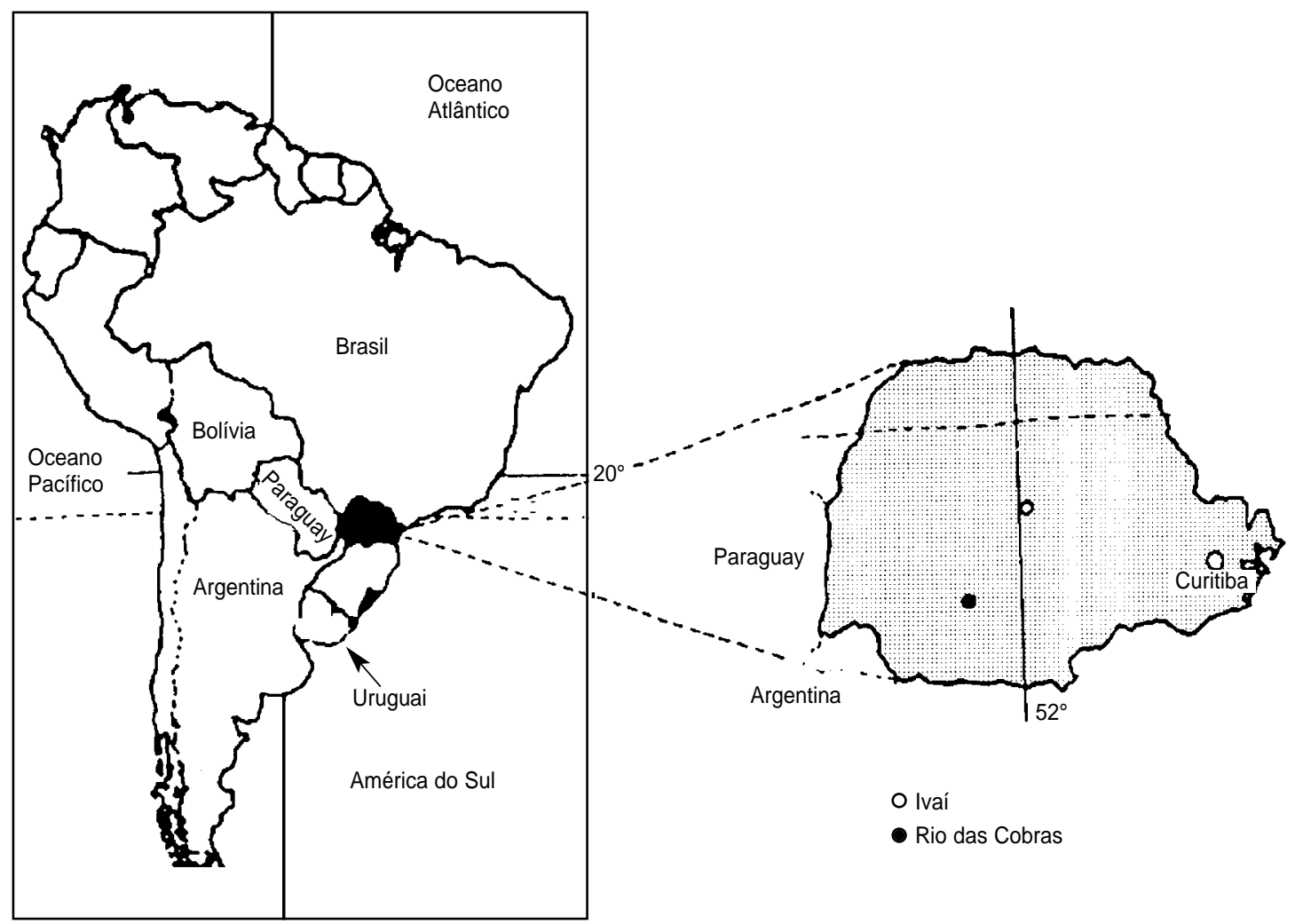


TABELA 1. Positividade de auto-anticorpos em índios das tribos Kaingang e Guarani e na população geral, Estado do Paraná, Brasila

\begin{tabular}{lcccc}
\hline Auto-anticorpos $^{b}$ & $\mathrm{KIV}(n=73)$ & $\mathrm{KRC}(n=103)$ & $\mathrm{GRC}(n=65)$ & População geral $(n=100)$ \\
\hline AML & $2(3 \%)$ & $8(8 \%)$ & $3(5 \%)$ & $2(2 \%)$ \\
AMA & $\mathrm{ND}$ & $\mathrm{ND}$ & $\mathrm{ND}$ & $\mathrm{ND}$ \\
ANA & $2(3 \%)$ & $1(1 \%)$ & $\mathrm{ND}$ & $1(1 \%)$ \\
LKM & $\mathrm{ND}$ & $\mathrm{ND}$ & $\mathrm{ND}$ & $\mathrm{ND}$ \\
CGP & $1(1 \%)$ & $\mathrm{ND}$ & $\mathrm{ND}$ & $1(1 \%)$ \\
AML + ANA & $\mathrm{ND}$ & $1(1 \%)$ & $1(1,5 \%)$ & $\mathrm{ND}$ \\
AML + AMA & $1(1 \%)$ & $\mathrm{ND}$ & $\mathrm{ND}$ & $\mathrm{ND}$ \\
AML + ANA + AMA & $\mathrm{ND}$ & $\mathrm{ND}$ & $2(3 \%)$ & $\mathrm{ND}$ \\
AML total & $3(4 \%)$ & $9(9 \%)^{\mathrm{d}}$ & $6(9 \%)^{\mathrm{d}}$ & $2(2 \%)$ \\
Total & $6(8 \%)$ & $10(10 \%)$ & $6(9 \%)$ & $4(4 \%)$ \\
\hline
\end{tabular}

a KIV = Kaingang do Rio Ivaí; KRC = Kaingang do Rio das Cobras; GRC = Guarani do Rio das Cobras.

${ }^{\mathrm{b}} \mathrm{AML}=$ anticorpos antimúsculo liso; $\mathrm{AMA}=$ anticorpos antimitocôndrias; $\mathrm{ANA}=$ anticorpos antinucleares; $\mathrm{LKM}=$ anticorpos antimicrossomas de fígado e rim; CGP = anticorpos anticélulas gástricas parietais.

${ }^{c} \mathrm{ND}=$ não detectável.

d $P=0,03$.

do Paraná (doadores de sangue). Todos apresentavam reações sorológicas negativas para sífilis, doença de Chagas, hepatites e AIDS. O critério de normalidade se baseou na análise rotineira de triagem de doadores, com concordância dos mesmos para utilização das amostras em estudos.

\section{Pesquisa de auto-anticorpos}

Todas as amostras de soro dos índios e dos controles foram investigadas para a presença dos auto-anticorpos antimúsculo liso (AML), antimitocôndrias (AMA), antinucleares (ANA), antimicrossomas de fígado e rim (LKM) e anticélulas gástricas parietais (CGP). Foi realizada uma reação de imunofluorescência indireta, conforme descrição anterior $(16,17)$, utilizando-se conjugado fluorescente anti-imunoglobulina total. As leituras foram realizadas em microscópio de fluorescência Karl Zeiss, sendo consideradas positivas as reações com títulos iguais ou superiores a 1:20 para os anticorpos AMA, ANA, LKM e CGP, e iguais ou superiores a 1:40 para os anticorpos AML.

\section{Substratos}

Para cada tipo de auto-anticorpo investigado utilizou-se um substrato específico para a reação de imunofluo- rescência indireta. Para a pesquisa de AML e CGP utilizou-se estômago de rato, para os ANA utilizou-se fígado de rato, para os AMA utilizou-se rim de rato e para os LKM, rim e fígado de rato. Após dissecção destes órgãos, os mesmos foram lavados exaustivamente em soro fisiológico, clivados e imersos em meio de inclusão para tecidos. Após congelamento imediato em nitrogênio líquido, os tecidos foram conservados em congelador a $-80{ }^{\circ} \mathrm{C}$. Posteriormente, foram realizados cortes criostáticos de 3 a $4 \mu \mathrm{m}$ de espessura, que foram mantidos a $-20^{\circ} \mathrm{C}$ até o momento da reação de imunofluorescência indireta.

Para a análise estatística foi empregado o teste do qui-quadrado $\left(\chi^{2}\right)$. O nível de significância adotado foi de $P<0,05$.

\section{RESULTADOS}

De 241 índios, 22 (9\%) apresentaram positividade para, no mínimo, um dos auto-anticorpos analisados, com títulos que variaram entre 1:20 e 1:160. Destes, 10 indivíduos pertenciam à população KRC; 6, à GRC; e 6, à KIV (tabela 1). Com relação ao grupo controle, quatro indivíduos mostraramse positivos para os auto-anticorpos analisados (4\%). A tabela 1 mostra o índice de positividade para todos os auto-anticorpos investigados nos três grupos indígenas em estudo, destacando-se a significativa prevalência dos AML nas populações KRC e GRC $(P=0,03)$ em relação à população controle analisada. A positividade para os demais auto-anticorpos não foi estatisticamente significativa, quando comparada aos controles.

A variação dos títulos de anticorpos das amostras positivas nas populações estudadas aparece na figura 2. Observou-se que, nas três tribos, os títulos mais altos foram para os anticorpos AML e AMA, que variaram entre 1:40 e 1:160. Para os anticorpos ANA, a variação foi de 1:20 a 1:80. Entre as populações KRC e KIV observou-se uma predominância da presença isolada de um só tipo de auto-anticorpo, sendo que cada grupo apresentou apenas um caso com mais de um auto-anticorpo simultaneamente. Por outro lado, na população GRC apenas três indivíduos apresentavam um único tipo de autoanticorpo, enquanto os demais apresentavam dois ou mais tipos de autoanticorpos simultaneamente (tabela 1).

\section{DISCUSSÃO}

As características multifatoriais das doenças auto-imunes, que envolvem aspectos imunológicos, ambientais e, predominantemente, genéticos, tornam de grande interesse os estudos voltados para grupos populacionais com características étnicas específicas.

A investigação laboratorial dos mais diversos auto-anticorpos tem proporcionado valiosas contribuições ao diagnóstico das diferentes doenças auto-imunes conhecidas. Nos últimos anos, inúmeros estudos de análise da presença de auto-anticorpos têm sido realizados em grupos populacionais distintos e em diversas faixas etárias $(18,19)$. Como a positividade de autoanticorpos é variável em diferentes populações, o conhecimento desses dados populacionais permite uma interpretação mais correta da presença dos auto-anticorpos e de seu significado clínico em doenças específicas nas diferentes populações.

Embora sejam inúmeros os relatos sobre problemas na área sociocultural 
FIGURA 2. Títulos de auto-anticorpos nas populações indígenas Kaingang e Guarani e na população controle, Estado do Paraná, Brasila

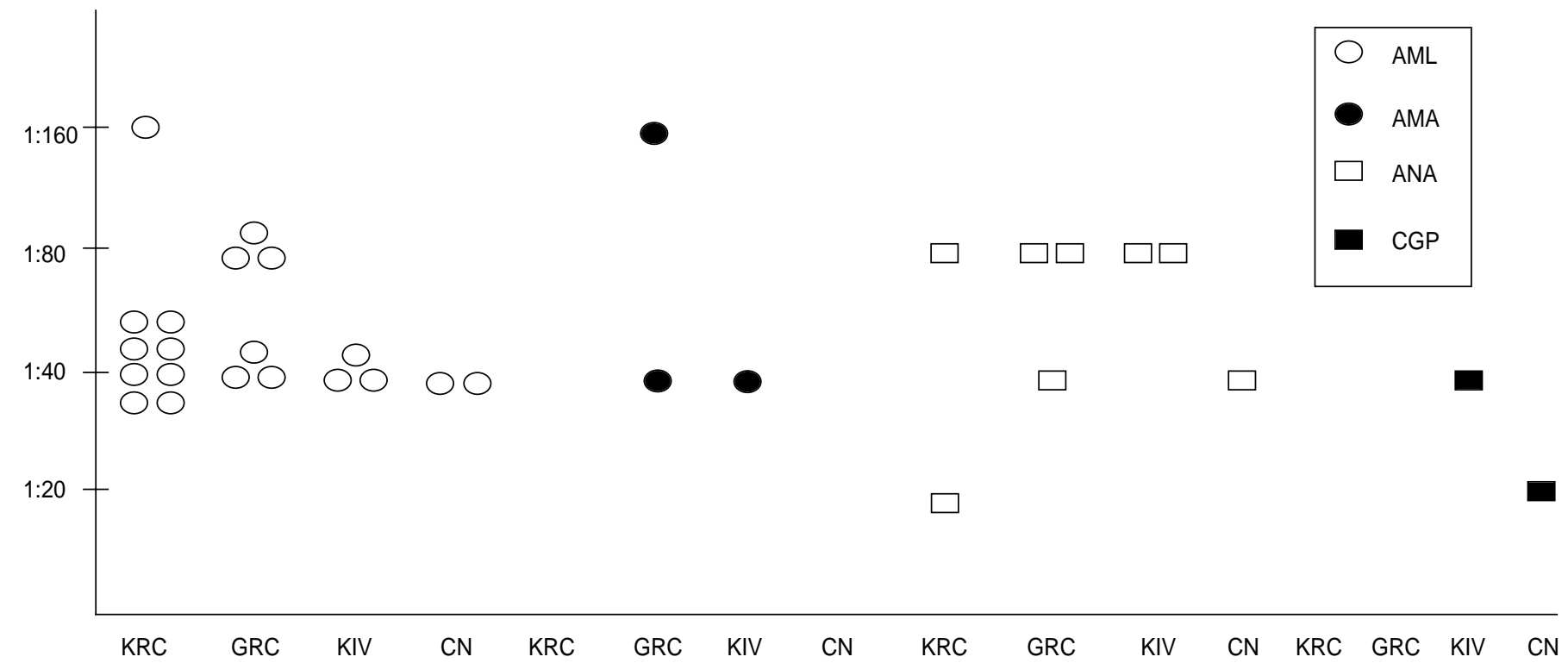

${ }^{a}$ KRC = Kaingang do Rio das Cobras; GRC = Guarani do Rio das Cobras; KIV = Kaingang do Rio Ivaí; $\mathrm{CN}=$ controles. AML = anticorpos antimúsculo liso; positividade em títulos iguais ou superiores a 1:40. AMA = anticorpos antimitocôndrias; ANA = anticorpos antinucleares; CGP = anticorpos anticélulas gástricas parietais. Para AMA, ANA e CGP: positividade em títulos iguais ou superiores a 1:20.

e da saúde em diferentes populações indígenas $(1,6,9,10)$, são raras as investigações sobre doenças de caráter auto-imune nestes grupos populacionais. Estudos realizados entre índios americanos do Arizona (20), Oklahoma (2) e do Noroeste do Pacífico (21) têm enfatizado a prevalência de artrite reumatóide, bem como o alto índice de mortalidade relacionado a esta doença nestas populações. Por outro lado, os estudos de Arnett et al. (4) com índios americanos do Oklahoma são voltados para a associação da esclerose sistêmica com antígenos de histocompatibilidade. Knouler et al. (14), por sua vez, avaliaram a presença de anticorpos anticélulas das ilhotas pancreáticas e diabetes melito em tribos de índios Pima, do Arizona.

Os estudos de Hans-Filho et al. (15) estão entre os raros relatos de doenças auto-imunes em populações indígenas do Brasil. Os autores caracterizaram um foco de fogo-selvagem em índios Terena, da reserva de Lima Verde, no Estado do Mato Grosso do Sul, Brasil. A prevalência da doença na população avaliada foi de 3\% (26 indivíduos em 1998). O fogo-selvagem é uma derma- tose caracterizada pela formação de vesículas subcorneanas e pela presença de auto-anticorpos antidesmogleína 1.

No presente estudo, foi realizada uma avaliação pioneira de autoanticorpos AML, AMA, ANA, LKM e CGP nos índios das tribos Kaingang e Guarani da região Sul do Brasil. A presença destes anticorpos pode estar relacionada a diferentes doenças autoimunes, como hepatites auto-imunes (AML, ANA e LKM), cirrose biliar primária (AMA), gastrite atrófica (CGP) e doenças do colágeno (ANA), entre outras. Por outro lado, os auto-anticorpos podem ocorrer na ausência de sinais clínicos.

Os resultados obtidos demonstraram uma positividade mais alta para os auto-anticorpos investigados entre os índios (9\%) quando comparados com a população controle (4\%). Além disso, observou-se uma diferença estatisticamente significativa na prevalência dos anticorpos antimúsculo liso (AML) nas populações KRC e GRC $(P=0,03)$ quando comparadas com a população geral (tabela 1). É interessante notar que aqueles indivíduos que apresentaram títulos mais eleva- dos de AML $(\geq 1: 80)$ apresentaram, simultaneamente, os anticorpos ANA e AMA, também em títulos mais eleva$\operatorname{dos}(\geq 1: 80)$.

De acordo com Büschenfelde et al. (22), a presença dos anticorpos AML em títulos elevados $(\geq 1: 80)$, isoladamente ou associados aos ANA, é sugestiva de hepatite auto-imune tipo I ou lupóide. Os anticorpos AMA podem estar presentes também nestes casos, freqüentemente em títulos moderados; quando presentes em títulos elevados, podem estar correlacionados com cirrose biliar primária.

Na presente investigação, é válido ressaltar que, por ocasião da coleta de sangue nas três populações indígenas, a avaliação médica realizada caracterizou como sadios todos os voluntários participantes do estudo. Tal aspecto faz com que se busque um maior entendimento para a presença destes auto-anticorpos na circulação destes indivíduos. Por serem dados laboratoriais isolados, estes resultados não permitem realizar uma maior correlação clínico/laboratorial, nem afirmar um diagnóstico de doença auto-imune. Para tal seria necessário um segui- 
mento criterioso e prolongado da população em estudo, considerando-se que, nestas doenças, a detecção dos auto-anticorpos precede às vezes até em anos as manifestações clínicas.

Alguns autores (23-26) têm relatado a presença de auto-anticorpos na circulação de pacientes com certas infecções virais, principalmente hepatites por vírus B e C (VHB e VHC). Possivelmente, o aparecimento destes autoanticorpos se deve a mecanismos de mimetismo molecular. A presença dos mesmos não demonstra, necessariamente, significado ou correlação clínica com alguma doença auto-imune. Ocasionalmente, o seguimento de pacientes geneticamente predispostos demonstra que uma infecção viral prévia pode representar o gatilho para uma futura doença auto-imune, com eventual detecção precoce de autoanticorpos.

Outros estudos têm demonstrado a presença de infecções por rotavírus em índios das tribos Surui e Karitiana, da Amazônia (27), e por vírus linfotrópico $\mathrm{T}$ humano do tipo II (HTLV-II) em índios Caiapó e Craô da região central do Brasil (28). Ainda, infecções pelos vírus das hepatites B e C foram descritas na tribo Parakanã (Estado do Pará) em 1994 (8). Investigações realizadas nos primeiros anos de contato desta tribo com populações não indígenas mostraram índices de infecção muito baixos ou ausentes, tanto para o VHB como para o VHC. Outro estudo soroepidemiológico para o vírus da hepatite B em quatro tribos da região Amazônica (Gavião, Surui, Zoro e Navate) demonstrou uma positividade entre 63 e $96 \%$ (7). Os autores relacionaram tais índices de infecção, nestas e em outras tribos da Amazônia, a um complexo de práticas culturais que favorecem a transmissão do VHB, tais como rituais com sangue, escarificações, tatuagens e processamento oral de alimentos, entre outros.

$\mathrm{Na}$ população de índios Kaingang e Guarani em estudo, Messias-Reason et al. (dados não publicados) demonstraram, através de uma avaliação soroepidemiológica para o $\mathrm{VHB}, \mathrm{VHC}$, citomegalovírus (CMV), vírus da imunodeficiência humana e Trypanosoma cruzi, uma positividade de $95 \%$ para o CMV. Em relação ao vírus da hepatite B, obtiveram $46 \%$ de positividade nas amostras que foram estudadas (19/41), deixando evidente que, assim como as populações indígenas da Amazônia (7, 8), também os índios do Sul do Brasil apresentam uma alta prevalência para o VHB. Pode-se supor que estas infecções virais, tanto pelo VHB como pelo CMV, através de mecanismos de mimetismo molecular, ou até por lesão tecidual, possam estar diretamente relacionadas à presença dos auto-anticorpos detectados no presente estudo.

Todos os aspectos anteriormente descritos deixam evidente que tanto os costumes indígenas, quanto o próprio processo de aculturação e convívio com populações não indígenas, têm exposto os índios a inúmeras doenças infecciosas, anteriormente inexistentes entre os mesmos. A presença de agentes infecciosos em indivíduos geneticamente predispostos pode ser o gatilho para futuras doenças de caráter crônico, hoje mundialmente tão freqüentes quanto as doenças auto-imunes. A detecção precoce e significativa de auto-anticorpos em indivíduos sadios, como no presente estudo, pode representar o princípio deste processo. Somente o acompanhamento clínico permitirá fazer qualquer afirmação futura.

\section{REFERÊNCIAS}

1. MacMillan HL, MacMillan AB, Offord DR, Dingle JL. Aboriginal health. Can Med Assoc J 1996;155(11):1569-1578.

2. Scofield RH, Fogle M, Rhoades ER, Harley JB. Rheumatoid arthritis in a United States Public Health Service Hospital in Oklahoma: serologic manifestations in rheumatoid arthritis vary among tribal groups. Arthritis Rheum 1996;39(2):283-286.

3. Becker TM, Wiggins C, Peek C, Key CR, Samet JM. Mortality from infectious diseases among New Mexico's American Indians, Hispanic whites, and other whites, 1958-87. Am J Public Health 1990;80(3):320-323.

4. Arnett FC, Howard RF, Tan F, Mouds JM, Bias WB, Durban E, et al. Increased prevalence of systemic sclerosis in a Native American tribe in Oklahoma: Association with an Amerindian HLA haplotype. Arthritis Rheum 1996;39(8):1362-1370.

5. Andrada-Serpa MJ, Dobbin JA, Gomes P, Linhares D, Azevedo JG, Hendriks J, et al. Incidence of retroviruses in some Brazilian groups. Immunol Lett 1988;18(1):15-18.

6. Naranjo P. Epidemic hecatomb in the New World. Allergy Proc 1992;13(5):237-241.
7. Coimbra Junior $C E$, Santos RV, Yoshida CF, Baptista ML, Flowers NM, Valle AC. Hepatitis $B$ epidemiology and cultural practices in Amerindian populations of Amazonia: the Tupi-Monde and the Xavante from Brazil. Soc Sci Med 1996;42(12):1735-1743.

8. Soares MC, Menezes RC, Martins SJ, Bensabath G. Epidemiology of hepatitis B, C and $D$ viruses among indigenous Parakanã tribe in the Eastern Brazilian Amazon Region. Bol Oficina Sanit Panam 1994;117(2):124-135.

9. Jackson MY. Nutrition in American Indian health: past, present, and future. J Am Diet Assoc 1986;86(11):1561-1565.

10. Hodge LG, Dufour DL. Cross-sectional growth of young Shipibo Indian children in eastern Peru. Am J Phys Anthropol 1991;84(1):35-41.

11. Petzl-Erler ML, Luz R, Sotomaior VS. The HLA polymorphism of two distinctive SouthAmerican Indian tribes: The Kaigang and the Guarani. Tissue Antigens 1993;41:227-237.

12. Messias IT, Petzl-Erler ML, Rehfeldt IR, Lima MT, Guerra LK. Variability of complement factor $\mathrm{B}$ and complement component $\mathrm{C} 3$ among Guarani Indians from Southern Brazil. Rev Brasil Genet 1993;16(3):803-809.
13. Guerra LK, Rehfeldt IR, Lima MT, Petzl-Erler ML, Messias IJ. BF and C3 genetic polymorphisms in Kaingang Indians from Southern Brazil. Hum Hered 1992;42(3):153-156.

14. Knowler WC, Bennett PH, Bottazzo GF, Doniach $\mathrm{D}$. Islet cell antibodies and diabetes mellitus in Pima Indians. Diabetologia 1979;17(3): 161-164.

15. Hans-Filho G, Santos V, Katayama JH, Aoki V, Rivitti EA, Sampaio SA, et al. An active focus of high prevalence of fogo selvagem on an Amerindian reservation in Brazil. Cooperative group on Fogo Selvagem research. J Invest Dermatol 1996;107(1):68-75.

16. Bigazzi PE, Rose NR. Pruebas para anticuerpos contra antígenos tissulares específicos. In: Rose NR, Friedman $\mathrm{H}$, eds. El laboratorio en inmunologia clínica. 2a ed. Buenos Aires: Editorial Medica Pan Americana; 1984. p. 968-979.

17. Rizzeto M, Swana G, Doniach D. Microsomal antibodies in active chronic hepatitis and other disorders. Clin Exp Immunol 1973; 15(3):331-344.

18. Levy-Marchal C, Tichet J, Fajardy Y. Islet cell antibodies in normal French schoolchildren. Diabetologia 1992;35(6):577-582 
19. Chakravarty K, Gray R, Webley M. Prevalence of anticardiolipin antibodies in the elderly British population. Posgrad Med J 1991; 67(786):358-361.

20. Jacobsson LT, Knowler WC, Pillemer S, Hanson RL, Pettitt DJ, Nelson RG, et al. Rheumatoid arthritis and mortality: A longitudinal study in Pima Indians. Arthritis Rheum 1993; 36(8):1045-1053.

21. Atkins C, Reuffel L, Roddy J, Platts M, Robinson $\mathrm{H}$, Ward R. Rheumatic disease in the Nuu-Chah-Nulth native Indians of the Pacific Northwest. J Rheumatol 1988;15(4):684-690.

22. Büschenfelde KHM, Lohse AW, Manns M, Poralla T. Autoimmunity and liver disease. Hepatology 1990;12(2):354-363.

23. Cassani F, Cataleta M, Valentini P, Muratori P, Giostra F, Francesconi R, et al. Serum autoantibodies in Chronic Hepatitis C: compari- son with Autoimmune Hepatitis and impact on the disease profile. Hepatology 1997; 26(3):561-566.

24. Clifford BD, Donahue D, Smith L, Cable E, Luttig B, Manns M, et al. High prevalence of serological markers of autoimmunity in patients with chronic hepatitis. Hepatology 1995;21(3):613-619.

25. Fried MW, Draguesku JO, Shindo M, Simpson LH, Banks SM, Hoofnagle JH, et al. Clinical and serological differentiation of Autoimmune and Hepatitis $\mathrm{C}$ virus related chronic hepatitis. Dig Dis and Science 1993;38(4): 631-636.

26. Gregorio GV, Jones H, Chouduri K, Vegnente A, Bortolotti F, Mieli-Vergani G, et al. Autoantibody prevalence in chronic hepatitis $B$ virus infection: effect of interferon alfa. Hepatology 1996;24(3):520-523.
27. Santos RV, Linhares AC, Coimbra Junior CE Epidemiological studies among Amerindians of Rondonia. IV. Serological survey for rotavirus among Surui and Karitiana. Rev Saude Publica 1991;25(3):230-232.

28. Maloney EM, Biggar RJ, Neel JV, Taylor ME, Hahn BH, Shaw GM, et al. Endemic human $\mathrm{T}$ cell lymphotropic virus type II infection among isolated Brazilian Amerindians. J Infect Dis 1992;166(1):100-107.

Manuscrito recebido em 28 de abril de 1999. Aceito em versão revisada em 22 de dezembro de 1999.

ABSTRACT This study investigated the autoantibody profile of 241 blood samples from 176 Kaingang and 65 Guarani Indians from three populations living on the Rio das Cobras and Ivaí reservations, in the state of Paraná, in southern Brazil. The presence of antimito-

Autoantibody profile among Kaingang and Guarani Indians in southern Brazil chondrial, antismooth muscle, antinuclear, antiparietal cell, and anti-liver-kidney microsome antibodies was determined by indirect immunofluorescence. These results were compared with samples from 100 healthy Caucasian individuals from the general population of the state. Total positivity was $9 \%$ for the indigenous population and $4 \%$ for the control population. The prevalence of antismooth muscle antibodies was significantly higher among the Guarani and Kaingang individuals from the Rio das Cobras reservation $(P=0.03)$. It is likely that the increased exposure that these indigenous Brazilians have to infectious diseases that were previously unknown to them comes from more contact with nonnative populations, growing acculturation, and cultural practices that include scarification and tattooing. The presence of autoantibodies in these Brazilian Indians may be related to mechanisms of molecular mimicry with viral or bacterial antigens. 